\title{
Improvement of the Hammer Drill Performance (Algerian Quarries Conditions)
}

\author{
Samia NEMOUCHI ${ }^{1}$, Elias HADJADJ AOUL ${ }^{2}$ \\ ${ }^{1}$ Mechanical Genetics Department, University of August 20, \\ 1955 Skikda21000Algeria, e-mail: Nemouchisamia@ hotmail.com \\ ${ }^{2}$ Electromechanical Systems Laboratory, Department of Electromechanical, \\ BadjiMokhtar - Annaba University, Annaba, Algeria, e-mail: hadjadj.elias@yahoo.fr \\ Manuscript received March 10, 2020; revised October 25, 2020.
}

\begin{abstract}
The factors which influence the performance characteristics of a hammer drill are examined; drilling data are analyzed to determine these factors. Methods for selecting the appropriate drilling are also highlighted. Two models are used in order to compare optimal drilling parameters. The main one is the machine output.
\end{abstract}

Keywords: Adjustment parameter, axial force, drilling speed, rock, productivity.

\section{Introduction}

Because of mining industry importance in the national economy, many researchers started to work to increase the production. It is impossible to speak about underground careers or mines, nor even tunnels, without speaking about the drilling machines [1], [2], [3]. Their role is significant and effective for and to the improvement of the production [4]. Several factors can affect drilling performances, which can be divided into controllable factors (rotation speed, air compressed forces) and factors which cannot be controlled (rock properties and geological patterns) [5], [6]. Thus, there have been improved the factors which make it possible to control and link the rate of penetration and the characteristics of the rocks, because the force of drilling and the speed excess influence the drilling tools' wear [7], [8], [9], [10] and thus increase production cost [11]. 


\section{Nomenclature}

$D$ : Piston diameter ( $\mathrm{mm})$;

$d_{1}$ : Diameter of the piston rod (mm);

$d_{2}$ : Diameter of the helical rod $(\mathrm{mm})$;

$G$ : Weight of the piston (kgf);

$l_{a}$ : Stroke of the piston $(\mathrm{mm})$;

$s_{a}$ : The useful surface of the piston to carry outward journey;

$s_{r}$ : The useful surface of the piston to carry return journey;

$p_{a}$ : Compressed air pressure in the cylinder inlet chamber. It is equal to the pressure in the supply network $\left(\mathrm{kgf} / \mathrm{cm}^{2}\right)$; $p_{e}$ : Compressed air pressure in the exhaust Chamber. We take 0.8 to $1.2\left(\mathrm{kgf} / \mathrm{cm}^{2}\right)$;

$k_{1}$ : Coefficient taking account of the losses by friction between the piston and the cylinder $\left(k_{1}=0.85\right.$ to 0.95$)$;

$T_{\text {aux }}$ : Downtime of the puncher due to technical causes ( $\mathrm{min})$;

$h$ : Height of the drilled hole (m);

$T_{\text {org: }}$ : Loss of time due to work organization;

$T_{f}$ : productive working time of a rotary hammer during a cycle, (min); $k_{2}$ : Coefficient taking into account friction and rotation losses of the foil ( $k_{2}=0.5$ to 0.7$)$;

$F_{a}$ : The force applied to the piston during the outward journey (kgf);

$E_{\text {ou: }}$ The energy of a piston stroke ( $\left.\mathrm{kgf} \cdot \mathrm{m}\right)$

$\sigma_{d}$ : Specific resistance of rock drilled according to the scale of Prof. Protodiakonov;

$d_{f}$ : Drilling diameter $(44 \mathrm{~mm})$;

$\xi_{e}$ : Efficiency of the energy transmission from the foil to the rock. We take (0.4 to 0.7$)$;

$f$ : The hardness of the rock

$u_{1}$ : Coefficient of friction between the cutter and the rock ( 0.3 to 0.5$)$;

$C_{e}$ : Blunt coefficient (1.2 to 1.3 );

$\alpha$ : Sharpening angle, degree;

$z$ : Number of cutting edges (1 to 3);

$K_{\text {tec }}$ : technical coefficient of a hammer drill;

$V_{\text {fexp: }}$ experimental forging speed $(\mathrm{m} / \mathrm{min})$;

$L$ : Footage of the drilled hole, (m);

$K_{\text {exp }}$ : Operating coefficient of a hammer drill

$\sigma_{\text {com: }}$ : Compressive strength.

\section{Basic functional parameters of the pneumatic perforator}

It is assumed that the compressed air pressure in the cylinder chambers at the inlet and during its exhaust is constant.

The basic parameters of the perforator are as follows:

Number of piston strokes per minute, $n_{c}$ (coups/min);

$>$ Number of foil turns per minute, $n_{r}(\mathrm{tr} / \mathrm{min})$;

$>$ Energy from a stroke of the piston, $E_{c}(\mathrm{kgf} \cdot \mathrm{m})$;

$>$ Specific consumption of compressed air, $C_{\text {air }}\left(\mathrm{m}^{3} / \mathrm{min}\right)$.

\section{Determination of the forces applied to the piston}

The useful surface of the piston for carrying out the outward journey is:

$$
s_{a}=\frac{\pi}{4} \cdot\left(D^{2}-d_{2}^{2}\right) .
$$

And for the return journey: 


$$
s_{r}=\frac{\pi}{4}\left(D^{2}-d_{1}^{2}\right) .
$$

The force applied to the piston during the outward journey is equal to

$$
F_{a}=\left(s_{a} \cdot p_{a}-s_{r} p_{e}\right) \cdot k_{1} .
$$

The energy of a piston stroke is equal to its kinetic energy of the piston

$$
E_{\text {ou }}=F_{a} \cdot l_{a} .
$$

\section{Choice of the rational operating regime of percussive drilling machine}

The best selection of the perforators depends mainly on the mining conditions, but it depends also on the rock properties and the tools' quality and machine performance. Many researchers have investigated (theoretically or experimentally) the percussion drilling, the researchers carried out tests of exploitation and laboratory tests for the goal to determine the indices of exploitation and the design features, Among researchers Karbatchev and Semenov studied the operation of the mining machinery [13].

\subsection{Drilling speed}

A: by the first method (A. Karbatchev):

$$
V_{f}=\frac{4 \cdot E_{\text {ou }} \cdot n_{c}}{\pi \cdot d^{2} \cdot \delta_{\text {comp }} \cdot\left(\operatorname{tg} \frac{\alpha}{2}+u_{1}\right) \cdot c_{e}}
$$

$B$ : by the second method (V. Semenov):

$$
V_{f}=\frac{1.3 \cdot E_{o u} \cdot n_{c}}{d_{f}^{2} \cdot \sigma_{d}} \cdot \xi_{e} .
$$

\subsection{The productivity of a rotary hammer}

Theoretical productivity is the number of meters of holes drilled during the time unit:

$$
Q_{\text {theo }}=60 \cdot V_{f} \cdot T_{P}
$$


The operating productivity depends on the degree of use of the technical possibilities of a rotary hammer under the concrete conditions of the exploitation:

$$
Q_{\text {exp }}=Q_{\text {tech }} \cdot k_{\text {exp }} \cdot T_{P} .
$$

\section{Results and discussion}

Table 1: Technical characteristics of the Atlas Copco pneumatic perforator type (RH658 L) [12]

\begin{tabular}{|c|c|c|}
\hline Parameters & Indices & Values \\
\hline Piston diameter & $D, \mathrm{~mm}$ & 65 \\
\hline Piston rod diameter & $d_{1}, \mathrm{~mm}$ & 40 \\
\hline Diameter of the helical rod & $d_{2}, \mathrm{~mm}$ & 30 \\
\hline Weight of piston & $G, \mathrm{kgf}$ & 2.4 \\
\hline Piston strokes & $l_{a}, \mathrm{~mm}$ & 36 \\
\hline Punch mass & $M, \mathrm{~kg}$ & 23 \\
\hline
\end{tabular}

Table 2: The input parameters of a rotary hammer

\begin{tabular}{|c|c|}
\hline$s_{a}\left(\mathrm{~cm}^{2}\right)$ & 2610 \\
\hline$s_{r}\left(\mathrm{~cm}^{2}\right)$ & 2060 \\
\hline$n_{c}($ coups $/ \mathrm{min})$ & 2222 \\
\hline
\end{tabular}

Table3: The variation of the energy of a stroke of the piston as a function of the pressure of the compressed air

\begin{tabular}{|c|c|c|}
\hline Test nr. & $\begin{array}{c}P_{a} \\
\left(\mathrm{kgf} / \mathrm{cm}^{2}\right)\end{array}$ & $\begin{array}{c}E_{\text {ou }} \\
(\mathrm{kgf} \cdot \mathrm{m})\end{array}$ \\
\hline Test 1 & 2 & 0.85 \\
\hline Test 2 & 2.5 & 1.205 \\
\hline Test 3 & 3 & 1.55 \\
\hline Test 4 & 3.5 & 1.91 \\
\hline Test 5 & 4 & 2.26 \\
\hline Test 6 & 4.5 & 2.614 \\
\hline Test 7 & 5 & 2.96 \\
\hline Test 8 & 5.5 & 3.319 \\
\hline Test 9 & 6 & 3.67 \\
\hline Test 10 & 6.5 & 4.024 \\
\hline Test 11 & 7 & 4.37 \\
\hline
\end{tabular}


Table4: The variation of the drilling speed as a function of the compressed air pressure by the two methods (A. Karbatchev, V. Semenov)

\begin{tabular}{|c|c|c|c|}
\hline Test nr. & $\begin{array}{c}P_{a} \\
\left(\mathrm{kgf} / \mathrm{cm}^{2}\right)\end{array}$ & $\begin{array}{c}V_{f s} \\
(\mathrm{~m} / \mathrm{min})\end{array}$ & $\begin{array}{c}V_{f k} \\
(\mathrm{~m} / \mathrm{min})\end{array}$ \\
\hline Test 1 & 2 & 0.093 & 0.17 \\
\hline Test 2 & 2.5 & 0.132 & 0.24 \\
\hline Test 3 & 3 & 0.170 & 0.31 \\
\hline Test 4 & 3.5 & 0.210 & 0.39 \\
\hline Test 5 & 4 & 0.248 & 0.46 \\
\hline Test 6 & 4.5 & 0.287 & 0.53 \\
\hline Test 7 & 5 & 0.325 & 0.60 \\
\hline Test 8 & 5.5 & 0.364 & 0.68 \\
\hline Test 9 & 6 & 0.403 & 0.75 \\
\hline Test 10 & 6.5 & 0.442 & 0.82 \\
\hline Test 11 & 7 & 0.480 & 0.89 \\
\hline
\end{tabular}

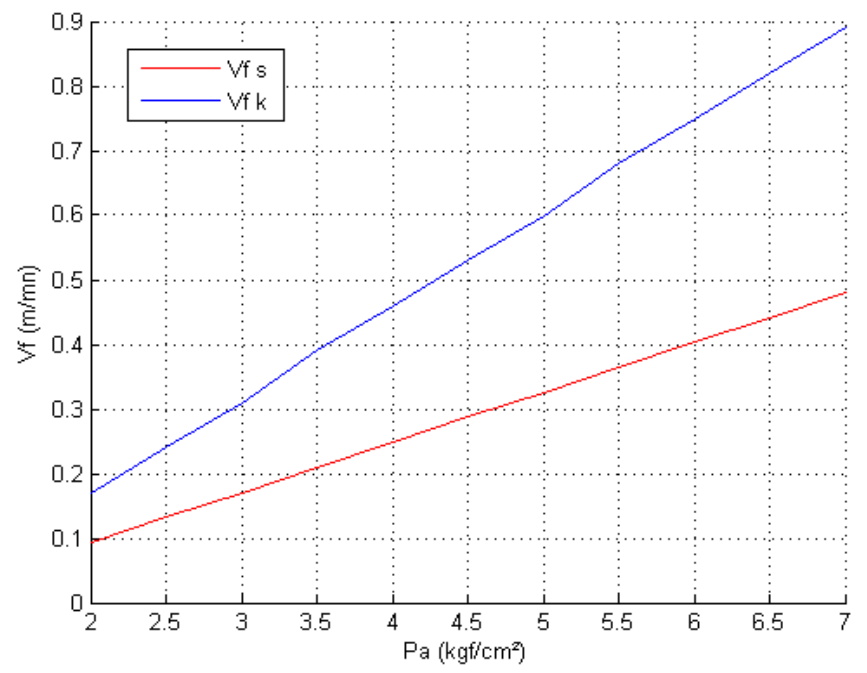

Figure 1: The variation of the drilling speed as a function of the compressed air pressure by the two methods (A. Karbatchev, V. Semenov)

During the experimental experiments the axial force varies, the time and the length are measured; the drilling speed is calculated by the following formula:

$$
V_{f \exp }=\frac{L}{T_{f}} \mathrm{~m} / \min .
$$


To process the results, we used the least squares method and checks with the correlation coefficient (see Fig. 2)

Table5: Result of the experimental study of a hammer drill working in the conditions of the (Hadja-Soud) quarry (Algeria)

\begin{tabular}{|c|c|c|}
\hline Test nr. & $\begin{array}{c}P_{a} \\
\left(\mathrm{kgf} / \mathrm{cm}^{2}\right)\end{array}$ & $\begin{array}{c}V_{\text {fexp }} \\
(\mathrm{m} / \mathrm{min})\end{array}$ \\
\hline Test 1 & 2 & 0.10 \\
\hline Test 2 & 2.5 & 0.13 \\
\hline Test 3 & 3 & 0.56 \\
\hline Test 4 & 3.5 & 0.28 \\
\hline Test 5 & 4 & 0.24 \\
\hline Test 6 & 4.5 & 0.38 \\
\hline Test 7 & 5 & 0.62 \\
\hline Test 8 & 5.5 & 0.40 \\
\hline Test 9 & 6 & 0.32 \\
\hline Test 10 & 6.5 & 0.36 \\
\hline Test 11 & 7 & 0.44 \\
\hline
\end{tabular}

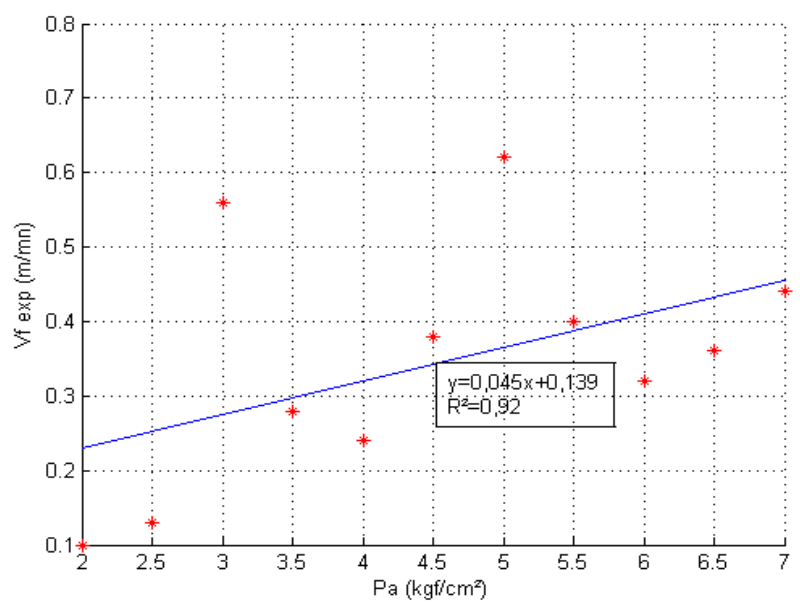

Figure2: the variation of the experimental forging speed as a function of the compressed air pressure

The results obtained from the productivity (yields) of a rotary hammer under the conditions of the (Hdjar -soud) quarry (Algeria). 
Table 6: Productivity (yields) by the method of (V. Semenov)

\begin{tabular}{|c|c|c|c|c|c|}
\hline Test nr. & $V_{f s}(\mathrm{~m} / \mathrm{min})$ & $h(\mathrm{~m})$ & $Q_{\text {theo }}(\mathrm{m} / \mathrm{post})$ & $K_{\exp }$ & $Q_{\text {exp }}(\mathrm{m} / \mathrm{post})$ \\
\hline Test 1 & 0.093 & 300 & 39.06 & 0.95 & 37.107 \\
\hline Test 2 & 0.13 & 250 & 54.6 & 0.93 & 50.77 \\
\hline Test 3 & 0.17 & 230 & 71.4 & 0.90 & 64.26 \\
\hline Test 4 & 0.21 & 200 & 88.2 & 0.87 & 76.73 \\
\hline Test 5 & 0.24 & 180 & 100.8 & 0.84 & 84.67 \\
\hline Test 6 & 0.28 & 170 & 117.6 & 0.81 & 95.25 \\
\hline Test 7 & 0.32 & 160 & 134.4 & 0.78 & 104.83 \\
\hline Test 8 & 0.36 & 150 & 151.2 & 0.75 & 113.4 \\
\hline Test 9 & 0.40 & 140 & 168 & 0.72 & 120.96 \\
\hline Test 10 & 0.44 & 130 & 184.8 & 0.68 & 125.664 \\
\hline Test 11 & 0.48 & 100 & 2016 & 0.60 & 120.96 \\
\hline
\end{tabular}

Table 7: Productivity (yields) by the method of (A. Karbatchev)

\begin{tabular}{|c|c|c|c|c|c|}
\hline Test nr. & $V_{f k}(\mathrm{~m} / \mathrm{min})$ & $h(\mathrm{~m})$ & $Q_{\text {theo }}(\mathrm{m} / \mathrm{post})$ & $K_{\text {exp }}$ & $Q_{\text {exp }}(\mathrm{m} / \mathrm{post})$ \\
\hline Test 1 & 0.17 & 300 & 39.06 & 0.92 & 65.68 \\
\hline Test 2 & 0.24 & 250 & 54.6 & 0.88 & 88.70 \\
\hline Test 3 & 0.31 & 230 & 71.4 & 0.84 & 109.36 \\
\hline Test 4 & 0.39 & 200 & 88.2 & 0.79 & 129.40 \\
\hline Test 5 & 0.46 & 180 & 100.8 & 0.74 & 142.96 \\
\hline Test 6 & 0.53 & 170 & 117.6 & 0.70 & 155.82 \\
\hline Test 7 & 0.60 & 160 & 134.4 & 0.66 & 166.32 \\
\hline Test 8 & 0.68 & 150 & 151.2 & 0.62 & 177.92 \\
\hline Test 9 & 0.75 & 140 & 168 & 0.58 & 182.7 \\
\hline Test 10 & 0.82 & 130 & 184.8 & 0.54 & 185.97 \\
\hline Test 11 & 0.89 & 100 & 201.6 & 0.45 & 168.21 \\
\hline
\end{tabular}

Table 8: Productivity (yields) by the method of (experimental)

\begin{tabular}{|c|c|c|c|c|c|}
\hline Test nr. & $V_{\text {fex }}(\mathrm{m} / \mathrm{min})$ & $h(\mathrm{~m})$ & $Q_{\text {theo }}(\mathrm{m} /$ post $)$ & $K_{\exp }$ & $Q_{\exp }(\mathrm{m} /$ post $)$ \\
\hline Test 1 & 0.23 & 300 & 96.6 & 0.90 & 86.94 \\
\hline Test 2 & 0.252 & 250 & 10.5 & 0.88 & 92.4 \\
\hline Test 3 & 0.275 & 230 & 113.4 & 0.86 & 97.52 \\
\hline Test 4 & 0.297 & 200 & 121.8 & 0.83 & 101.09 \\
\hline Test 5 & 0.32 & 180 & 134.4 & 0.80 & 107.52 \\
\hline Test 6 & 0.342 & 170 & 142.8 & 0.78 & 111.38 \\
\hline Test 7 & 0.365 & 160 & 151.2 & 0.76 & 114.91 \\
\hline Test 8 & 0.387 & 150 & 159.6 & 0.74 & 118.10 \\
\hline Test 9 & 0.41 & 140 & 172.2 & 0.71 & 122.26 \\
\hline Test 10 & 0.432 & 130 & 180.6 & 0.96 & 124.61 \\
\hline Test 11 & 0.455 & 100 & 189 & 0.62 & 117.18 \\
\hline
\end{tabular}




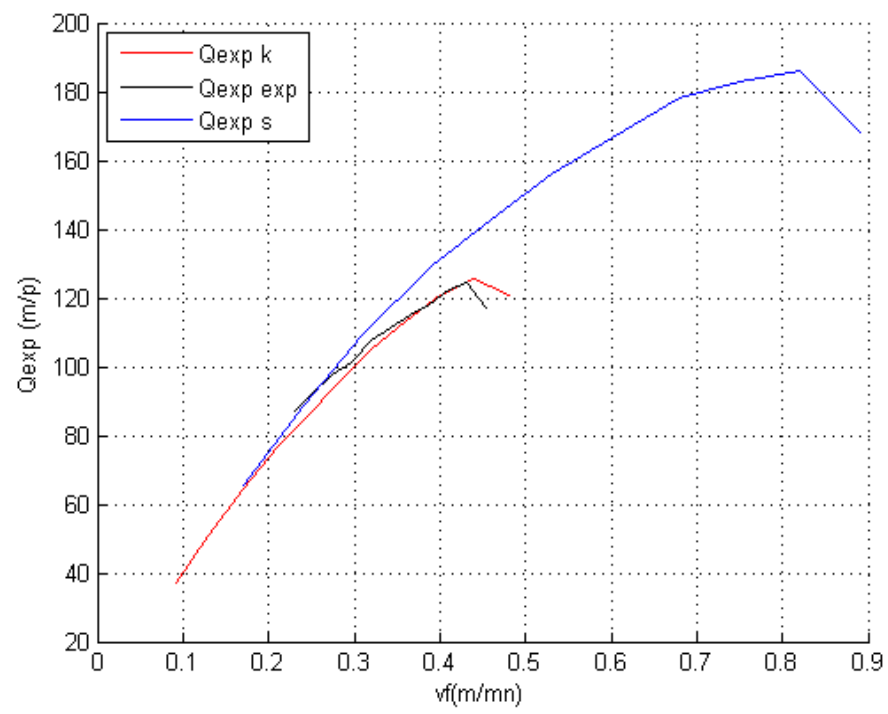

Figure3: Graphical comparison of the results of calculation of the productivity (yields) of exploitation by the three methods (A. Karbatchev, V. Semenov, experimental)

\section{Conclusion}

The rational parameters of the operating regime of percussive drilling machines in the (Hdjar-soud) quarry conditions are presented in Table 9.

Table 9: Optimal parameters of a hammer drill

\begin{tabular}{|c|c|c|c|c|}
\hline \multirow[b]{2}{*}{$\begin{array}{c}P_{a} \\
\mathrm{Kgf} / \mathrm{cm}^{2}\end{array}$} & \multirow[b]{2}{*}{$\begin{array}{c}E_{\text {ou }} \\
(\mathrm{kgf} \cdot \mathrm{m})\end{array}$} & \multirow[b]{2}{*}{$\begin{array}{c}V_{f} \\
(\mathrm{~m} / \mathrm{min})\end{array}$} & \multicolumn{2}{|c|}{ productivity } \\
\hline & & & $\begin{array}{c}Q_{\text {the }} \\
\text { (m/post) }\end{array}$ & $\begin{array}{c}Q_{\exp } \\
\text { (m/post) }\end{array}$ \\
\hline 6.5 & 4.02 & 0.44 & 184.8 & 125.664 \\
\hline
\end{tabular}

The main objective of the present work is to underline the importance of the functioning parameters of the drilling machines and the choice of their quality. Based on the results obtained, it can be drawn that the Karbatchev method is better than Semenov one.

According to the results obtained from the regression model proposed, it can be concluded that there is a strong linear correlation between the speed and air pressure (correlation coefficient values $R \geq 0.92$ ). A good agreement between theory and experiment is clearly expressed. 


\section{References}

[1] Khochman, L, Hadjadj, A.E., "New Méthodologie Sélection of Shilling Machines", Arian Journal of Information Technologie, 5 (12), pp. 1310-1312, 2006.

[2] Mehennaoui, S., Khochemane, L., "Optimization of setting parameters of a rotary drilling rig using Sim Hydraulics Toolbox", J. Contemporary Engineering Sciences, vol.8, no.3, pp. 115-120, 2015.

[3] Derdour, F. Z., Kezza, M., "The optimization of the operation parameters of a rotary percussion shilling machine using the Taguchi methods", World Journal of Engineering, vol. 15, lssue 1, pp.62-69, 2017.

[4] Hoseinie, S. H., Aghababaei, H., Pourrahimian, Y., "Development of a new classification system for assessing of rock mass drillability index (RDi)", International Journal of Rock Mechanics \& Mining Sciences, vol. 45, pp. 1-10, 2008.

[5] Yarali, O., Kahraman, S., "The drillability assessment of rocks using the different brittleness values", Tunnelling and Underground Space Technology, vol. 26, pp. 406-414, 2011.

[6] Yaşar, E., Ranjith, P. G., Viete, D. R., "An experimental investigation into the drilling and physico-mechanical properties of a rock-like brittle material", Journal of Petroleum Science and Engineering, vol. 76, pp. 185-193, 2011.

[7] Richard, T., Germai, C., Detournay, E., "A simplified model to explore the robot cause of stick-slip vibrations in shilling system within drag bits", Journal of Sound and Vibration, vol. 305, pp. 432-456, 2007.

[8] Afeni, T. B., "Optimization of drilling and blasting operations in an open pit mine - the SOMAIR experience”, J. Mining Science and Technology, vol. 19, pp. 736-739, 2009.

[9] Yue, Z. Q., Lee, C. F., Law, K. T., Tham, L. G., "Automatic monitoring of rotary-percussive drilling for ground characterization-illustrated by a case example in Hong Kong", International Journal of Rock Mechanics \& Mining Sciences, vol. 41, pp. 573-612, 2004.

[10] Huang, B.-W., Kuang, J.-H., Yu, P., "Effect of crack on Trilling vibration", Journal of Sound and Vibration, vol. 322, pp. 1100-1116, 2009.

[11] Ryu, S., Cho, J.-W., Park, J.-Y., Lee, J.-W., Jeong, M.-S., Song, C.-H., Kim, J.-G., and Song, J.-J., "Optimum Operating Conditions of a Multi-Hammer Drilling Machine Assessed using a Linear Percussion Test", International Journal of Precision Engineering and Manufacturing, Vol. 16, No. 7, pp. 1415-1422, 2015.

[12] https://www.atlascopco.com< handheld < rok-drills< <neumatic-rok-drills

[13] Rabbouche, Z., Khochemane, L., Bennis, O., "Study of the determination of the rational operating regime of percussion drilling machines", International Journal of Engineering and Technology (IJET), Vol. 9, No. 2, Apr-May 2017. 